\title{
Experiencing Foster Care-Happiness and Wellbeing of Institutionalised Children
}

\author{
Saleena.M' ${ }^{1}$, Suja M.K ${ }^{2}$ \\ ${ }^{1}$ PhD scholar, ${ }^{2}$ Associate Professor, Department of Social Work, Amrita School of Engineering, Coimbatore, \\ Amrita Vishwa Vidyapeetham India
}

\begin{abstract}
The institutionalised children are the most vulnerable group in our society and they show many problems.To improve institutionalized children's protection there is an urgent need to understand the various issues faced by them and find out remedial measures. To ensure the care and protection of institutionalised children,the Kerala state government has launched foster care scheme under the department of women and child development.This study is based on the group discussion by researcher with the institutionalised children who are experiencing foster care.

The objective of the study is to understand the foster care experience of institutionalised children and also understand their happiness and wellbeing during the period of foster caring. The researcher selected focus group discussion method for collecting data.Researcher made two focus group discussion with institutionalised children who are experiencing foster care.The group include six girls and another group contain seven boys. Hence the total respondents were thirteen in number

Result and Conclusion:The experience of foster care children from foster families are very positive.They are satisfied with the care,love and facilities which are provided by their foster parents and sibilings. The children can transform their lives during the foster care period.Many children have the wish to return their foster family.
\end{abstract}

Keywords: Experience, foster care, happiness, wellbeing,institutionalised children.

\section{Introduction}

Children's home is an institution established for the protection,education, training and rehabilitation of children in need of care and protection as defined in section 2(D) of the Juvenile Justice Act 2015. These institutions are the home to the children who are in need of care and protection. The children from socially,economically and educationally backward family in our society, homeless children, children released from child labour,street children, children whom were saved by child line are in need of care and protection. The institutionalised children's admission is permitted by the order of the Child welfare committee. These children are most marginalized and vulnerable group in our society. Adequate support and care is an essential component for emotional, mental and physical wellbeing of institutionalised children. During vacation period an alternate care provided for the wellbeing of children .These alternate care is provided in India as per the guidelines of Ministry of women and child development. It is carried out by District child protection unit and the foster care children were placed for foster care by the individual case assement of child welfare committee.

Foster care is the alternate care for children in need of care and protection in the family environment other than the child's biological family. Care giver of foster family is referred as foster parent and they are approved by the state government under the guidelines of foster care system. Foster parents has been selected by child welfare committee. Family has vital role in the behavior modification of children. It is important for the overall development of children. The National Policy for children 2013 said that all children have right to grow 
in a family atmosphere which provide love, warmth,care ,happiness and understanding ${ }^{1}$.

Fostering is a temporary residential care system for institutionalised children.They live with unrelated or extended family. In this System their biological parents do not lose their parental rights. Foster care is the placement of child till he or she is able to return to their own family. The maximum duration of foster care is one year ${ }^{2}$.foster care can provide more opportunity and a better quality of life.

The children who are placed in a foster home shows transformation in their lives. This transformation happens not only in children but also in foster parents. Becoming a foster parent is rewarding and it is a calling for the majority of carers more than a job.Obiviously there are lows and highs, but the positive side of both partners overcome the negatives ones ${ }^{3}$.

Foster care provides stability and secure environment,Acadamic stability, family life and strong family contact to the children .Children under foster care intervention had higher level of wellbeing, Attention and positive effect when compared to children who remain in institution ${ }^{4}$.Children's future wellbeing only happen within a family environment which provides care, love and affection, happiness.Lack of care caused many behavioural problem in children. The institutional children shows growth suppression, impairement in psychological, emotional and social development when compared to non institutionalized children. The children who are experiencing the foster care can recover from these developmental impairements.A well designed foster care programme can make high quality improvement in institutionalised children ${ }^{5}$.

Foster care may be short term or long term depending upon the needs of the child. The duration of the foster care has been based on the individual case assessment by child welfare committee. Based on the individual care plan, institutionalized children in the age group of six to eighteen years shall be placed in foster care. The age group zero to six years will not be considered for placement.They should be considered for permanent adoption.According to the report of U S Department of Health and Human service children's beauro ,In 2015 22 percent of total foster care children were adopted by their foster parents. The parents who are terminally ill couldn't take their children. In this situation also the children should be provided foster care with their permission of their biological parents ${ }^{6}$.

In 2018, there are approximately 140 couples and in 2019 approximately 200 couples in Kerala were approved as foster parents by District child protection unit and child welfare committee. The children who are wishing to foster family are sent to different families under the guidelines of Juvenile Justice Act 2015.Foster care can be two month summer vacation programme. But the child and foster parents are interested to extend the period of staying, the child welfare committee will give permission to extend the duration. Wellbeing is not the state of merely the absence of diseases and also an individual can lead his life with satisfaction. Wellbeing is associated with an individual's physical health ,mental health and resilence,that is the ability to cope with unfamiliar situations. The pleasurable and enjoying moments directly leads to the transformation of institutionalised children. The psycho social intervention method has great influence in the behavioural change of children. Hence the foster care programme helps the wellbeing of children in need of care and protection.

\section{Methodology}

This study was conducted in two children's home under the department of women and child development of Kerala government.One children's home was for boys and another children's home was for Girls.In this qualitative study, focus group discussion was used for understanding the experience of foster care among institutionalized children. Two focus group discussions were held .One group include six girls and another group contain seven boys. Thus the total number of respondents were thirteen in number. The collected opinion from all respondents are reviewed for this study.

From the words of Sukanya (name changed for privacy) thirteen year old girl,researcher understood that she enjoyed the vacation with caring parents and siblings. She experienced the love and warmth of the family during the two month vacation period. Sukanya said that she did not feel loneliness and she got brother and sister from there."when Mom and Pappa went for outings and family functions they protected and loved me as their own child" she said.Foster family provide warmth and moments of enjoyment to foster care children.Because 
of their love and affection many children told that they wished to go their foster family again.

Akash (name changed for privacy) eight year old boy said that Mom and Pappa gave him gifts, new school bag ,chapel and dresses .And also they provide enjoying moments during beach trip. "I got a loving elder sister" he said.Appukuttan, (Name changed for privacy) five year old boy came to the orphanage 1year back and his father was a drug addict.Mother abandoned him. The boy was very happy to be with a family.He said,"I like the new house and the new parents promised that they will take me if I study well". The boy was studying well as he wants to go from children home to the family."I got new shirt and shoes.My father gave me chappals". The boy was curious of the things given by the new family.He was in a wonder world seeing all the new facilities and comfort which he never got from his biological parents. Because of the strong bond between the foster care and foster child,some times they couldn't be separated.The memories of the happy moments make them feel to go back to their foster families.In this situation foster care period may be extended.Foster family also provide academic stability.

Lakshmi(name changed)12 year old girl was sent to teacher's family who have no children, She liked the place very much and her only concern is that there is no one to play with. She liked the puppy and pussy cat in that home and said."Teacher dad and Teacher mom got a new pet, and that is me".Lakshmi is very much attached to the teacher couple and wish to stay back as she has not experienced a familial atmosphere.Lakshmi is a born orphan and she was raised in an orphanage later she was handed over to the children's home.Lakshmi for the first time in her life came to know what is a "home"and how she would be feeling good and comfort if she had a family.

Selva Kumar (name changed,14 yrs)is a boy from Tamil Nadu who came with his uncle and aunt for coolie works.His biological parents are alcohol addicted and uncle took him with him for manual labour.The child line people saw the boy and was given to the orphanage. "I want to go with a Tamil family.I like Tamil food.The new malayalee parents are good,but I want Tamil People".Selva Kumar Said.The children home people have promised him to find a Tamil family during the next time.Selva Kumar felt this is a fresh experience where he was fully mingled with a malayalee family consisting of father, mother and two children. There were also grand parents who were strict and asked him to take bath twice a day and also to do prayers in the morning and evening.Keeping this aside Selva Kumar is so happy to have a big house and family and to travel in a car like other children. Foster parents ensured care and security to the children.

Rani(name changed ,6yrs) is the charming beauty of the children's home. She went with a family having three male children. The parents were longing for a female child and happened to see Rani and they sent their readiness to accept Rani as their foster child, Rani is still in the wonder world. She always wears the dress given by the new parents. From the words of Rani "I got three new friends to play with and the elder brother take me outside in the car". Rani is so exited to be in the family and she wished to get more brothers like these."I like the two new brothers,so that I don't want to do any work".Foster care helped the institutionalised children to become have a sense of belonging and the feeling of lonliness cleared up in their mind. They experienced the pleasing moments,individual care and learned moral values from their foster family.

Rahman (name changed) fourteen year old boy wished to drive cars and bikes and his dream was fulfilled when his new parents taught him the basic lessons of driving "I want to be eighteen years very soon so that I can get license and my new parents will give me the car". Now they allowed him to take the car in the courtyard only. "I will study very well and will buy a benz very soon.I want to take my new parents for a ride".He said this innocent words. Rahman was sent with a family who don't have a family who don't have male children. They only had a daughter and she is married and settled in America. They wished to have a child in their home and so they happily agreed to take Rahman with them.Rahman is always explaining how he was treated by the new parents and all other friends wished to see his new parents.He also bought sweets and gifts for his orphanage friends. These parents visit Rahman and also they often call him. They have also promised a trip soon.Through the focus group discussion many of the children told that they want to go back to their foster family again.from their words researcher understood 
that the foster care provide the children physical,social ,emotional and psychological wellbeing.The foster parents and sibilings lives in the heart of the children who were taken into foster family.Every pleasurable moments were in their mind. "I got a good family ,next time I wish to go another family ,because I want to experience the happiest moments of various families". Neenu ,eight year old girl said.

\section{Findings}

Foster care is provided to the children who are of the age group between six to eighteen.During these period all children pass through some maladjustment and difficulties.Children's emotional, physical and mental difficulties may clear up completely only with an adequate support system.From the stand point of the child's physical, psychological and social wellbeing proper supportive relationships and environments are very important. Reviewing all cases in this study researcher understood that all children who are experiencig foster care got an opportunity to spend happiest moments with good family. These children got these effective parental care because of the screening of foster family by child welfare committee.when the screening is not carried out,it will negatively affect the children's mental health and over all well being.only when foster parents do their responsibility in effective manner,the children are satisfied to stay with them

The adequate support of child hood has great influence in the wellbeing and health of a person. Children's wellbeing is related with the environment which they live in. The social relationships are also of great importance in the holistic wellbeing of children. The parental care and housing conditions have the vital role in the development of children.

Foster care programme help the homeless children to get housing ,emotional support, and to acquire life skills.Every child deserve a chance at belonging ,safety,happiness and love.Children who are the victim of natural disasters,substance use,trafficked children from economically and socially backward family,street children etc belongs under the umbrella of children in need of care and protection.Providing residential care system such as foster care is a great exposure to the holistic development of these children.It also provide happy moments to foster parents. Through foster care the children got safe,happy,comfortable and healthy atmosphere.The foster parents ensures the safe and comfortable zone to foster children.Thus the level of happiness and wellbeing was higher in foster care children during their fostering period.Many of the children had a desire to return back to foster family rather than their biological family. "I can't leave my mother and father,even if my biological mother come back to me,I like to stay with them one more year"sithara(name changed for privacy) said.From her words researcher realized that the warmth, love and affection of foster parents leads the children to become more happy.Foster family gifted the new clothes, school materials, books and bags to the academic year for children. It gives a lot of pleasure to children and they acquire academic stability. During the conversation with the district child protection officer the researcher reached at the conclusion that there is no bad experience faced by foster children with their foster parents because the DCPCU placed the children only after the detailed enquiry about foster family.

Through these vaccation family, children learn the moral values, sense of belonging and they have an opportunity to know more about how a family function, how to behave while interacting with others and adjust with unfamiliar situations. The warmth of the family provide them all these qualities.In Kerala foster care system is known as "sanadha bhalyam".Sandha bhalyam is very fruitful programme for the happiness and wellbeing of institutionalised children.

\section{Discussion and Conclusion}

Childhood experience is the root of the future health and wellbeing of a person.Institutionalised children face lot of problems. One of the intervention programme is Foster care system. Through foster care children got shelter,clothing and adequate food.Foster care parents provided warmth, love and affection,support,care and gave opportunities for child's over all physical,emotional and mental health development.They ensure vocational training and education based on the interests of the child.Foster family protected the children from abuse ,maltreatment and exploitation. They also provide treatment in emergency situation.Foster care system in Kerala had a great impact on the development of foster children as well as foster parents.Both parties got a lot of pleasure and enjoyment. 
Ethical Clearance- Taken from Human Ethics Committee, Dept. of Social Work,

AmritaVishwaVidyapeetham, Coimbatore, Tamil Nadu, India

\section{Source of Funding- Self}

\section{Conflict of Interest- Nil}

\section{References}

1. The National Policy For Children ;2013

2. Wed .Kerala.gov.in
3. John, what are the benefits of fostering a child? ;2016

4. Melissa M Ghera,Peter J Marshall,Nathan A Fox,Charles H zeanah,Charles A Nelson,Anna T Smyke \& Donald Guthrie, The effects of foster care intervention on socially deprived institutionalized children's attention and positive effect:Results from the BEIP study,Journal of child psychology and psychiatry;2009;50 (3): 246- 253

5. Ann Berens, Charles Nelson ,Ending institutionalisation of children;2015

6. Model guidelines for foster care ,Ministry of women and child development; 2015 